\title{
Targeting efficiencies among trade show nonattendees
}

Received (in revised form): 25th May, 2007

\section{Carmen Berné}

is Professor of Marketing at the University of Zaragoza (Spain) as a member of the Department of Business. She has taught business and marketing courses since 1987 and was guest professor at the Oxford Institute of Retailing Management, University of Oxford (UK), in 2004. Currently, she is a member of the CREVALOR research group.

\section{Ma Esperanza García-Uceda}

earned her PhD in marketing of trade shows in 2005. She teaches marketing in the Department of Business at the University of Zaragoza (Spain).

Keywords potential market, target segment, trade show visitors, trade show marketing

\begin{abstract}
When managers define target markets on the basis of market segments, a discrepancy arises between the potential and target markets bringing up two major questions: how much of the nonresponse of the targeted market comes from individuals - who cannot be considered potential customers - and, can we consider the aggregate data of targeted individuals not responding to the marketing effort a reliable source for the acquisition of customers? This issue is analysed in one empirical setting - trade shows targeting retail firms. We first use the aggregate data to estimate, by means of a confirmatory factorial analysis, a model reflecting the reasons involved in nonattendance at trade shows. Then, a cluster analysis is made to identify the individuals actually not interested in trade shows. Our results show that 20 per cent of the targeted retailers were not potential customers. Finally, we found that excluding these individuals resulted in significant and relevant differences in the model estimation. These findings provide managerial implications to improve the design of marketing strategies pursuing the acquisition of new customers and visitors. This paper fills a gap in trade show literature by analysing the under-researched issue of nonattendees and its impact on organisers' targeting decisions.

Journal of Targeting, Measurement and Analysis for Marketing (2007) 15, 146-157. doi:10.1057/palgrave.jt.5750042
\end{abstract}

\section{INTRODUCTION}

The trade show sector has evolved from a sales orientation - in which the focus was the sales objectives to a broader concept of interactive communication objectives. Today, trade shows foster the establishment of networks - both vertical and horizontal ${ }^{1}$ — which are not limited to the geographical framework in which they take place. $^{2}$

Correspondence: Carmen Berné, Department of Economics and Business Management, Faculty of Economic Sciences, University of Zaragoza, C/Gran Vía, 2. Zaragoza 50005, Spain.

Tel: 34976762721 ;

Fax: 34976 761767;

E-mail: cberne@unizar.es
In this dynamic, the organisers of trade show events have changed their orientation from the narrow role of facilitating the physical space to a broader role of being a catalyst in the encounter of supply and demand. Also, their focus driven mainly towards the exhibitor has now become more balanced by switching some of their resources to improve the effectiveness in the acquisition of the adequate number and quality of visitors. Partly, this evolution has been accelerated by the increasing presence of private organisers complementing and/or competing with public trade show organisers.

In this market environment, organisers need to differentiate their events and to address their 
communication efforts to targeted segments of potential visitors. As a consequence, trade shows are now more diversified and have increased in number; they seek thematic specialisation addressed to narrower market segments, whereas potential new visitors emerge - some studies estimate that about 50 per cent of the visitors to a show do it for the first time (CEIR study cited in $\mathrm{AFE}^{3}$ ). In this competitive environment, in order to set up a successful trade show and line up exhibitors, the organisers need to guarantee the ability of the show to attract a large number of visitors, ${ }^{4}$ and quantify qualified audiences. ${ }^{5}$

But a common approach to the marketing planning process is that trade show organisers usually set their target markets on the basis of broad segments. They first cluster the individuals in different segments in all of which the average individual would be interested in the product/ service. Then they select all or some of the segments according to their strategic goals. Thus, the target market is defined on the basis of market segments, but with the understanding that a part of each segment may not be part of the actual potential market, that is, there are individuals who are not interested in the product. This is particularly true when the cost of assessing the probability of one targeted visitor to be part of the potential market clearly exceeds the cost of not doing it. An unavoidable discrepancy arises between the potential and target markets that often results in a relevant part of the latter not being a part of the potential market.

This discrepancy brings two major questions, which are the objectives of this paper. First, how much of the nonresponse of the targeted market comes from the actual lack of interest in trade shows, rather than from the competitive positioning of the organiser's venue? In other words, how much of the present target market is not part of the potential market? Secondly, under these circumstances, can we consider the aggregate data of targeted individuals not responding to the marketing effort a reliable source for decision making oriented towards the acquisition of visitors?
To tackle these two major questions, we will use an empirical setting - the organisers of trade shows - very sensitive to the problem of addressing the marketing efforts to the right potential customers. We will provide the perspective of marketing responsibilities of trade show managers who are particularly interested, not just in focusing on predefined segments but also in addressing their marketing efforts to potential customers. First, we will discuss the relevance of this issue in the trade show sector and we will provide the antecedents in the research. Secondly, we will provide an analysis of the key reasons why targeted visitors to professional trade shows decide not to attend. The analytical methodology uses confirmatory factorial analysis (CFA) based on the responses obtained in a survey conducted on a sample of retailers who expressed their opinion about the relevance of factors determining the nonattendance decision.

In the last part of the paper, we will provide a precise answer to the questions in our objectives: the percentage of the nonattendees of the targeted segment, which is not part of the potential market, and the differences that an accurate identification of the potential market would bring to the marketing efforts of organisers. For these purposes, a cluster analysis will be applied to the nonvisitors to identify the existence of nonpotential customers and then a multi-group factor analysis will be used to view the differences in the reasons for nonattendance at the show among potential and nonpotential customers.

\section{PREVIOUS RESEARCH AND NONATTENDING DECISION CRITERIA}

\section{Previous research}

When considering customer retention and acquisition as the two major goals of the marketing activity, ${ }^{6}$ the research on marketing productivity analysis is skewed towards customer retention..$^{7-9}$ This fact has led to a lack of attention to some important problems in the marketing productivity of activities involved in customer acquisition, and particularly in the segmentation-targeting process. 
In common practice, targeted segments are addressed as a whole without considering the very likely outcome that a vast part of communication efforts reach individuals with no interest at all in the company's offering. The importance relies not only on the waste of marketing budget dedicated to communicate the marketing offer to the part of the target segment not actually interested, but in the lack of marketing effectiveness in developing the marketing strategy to attract new customers.

In the trade show sector, the management of commercial communication prior to the holding of the event is the primary responsibility of the organiser and, secondarily, of the exhibitors. The organiser needs to inform and attract the target audience of the show in question; both exhibitors and visitors. Of course, attracting visitors is an important inducement to capturing the attention of exhibitors. Trade shows, as events that disseminate information about the market and supply alternatives, are effective means to lessen the risk of decision making under uncertainty conditions, leading to improvements in the confidence of the industrial buyer, ${ }^{10,11}$ and to positive yields of sales, customers, information and image of exhibitors. ${ }^{12}$ But such outcomes are only possible if the right exhibitors meet the right visitors. ${ }^{13}$

Therefore, the identification and understanding of potential customers' motivations to attend a trade show is essential for exhibitors to effectively and efficiently reach the objectives of their participation. ${ }^{1}$ These facts suggest that the knowledge of visitor behaviour is one of the success keys of any trade show. Consequently, most of the research has been focused on actual visitors of trade shows, on their reasons for having done so and on the chances to repeat in future events (see Smith et al. ${ }^{2}$ ).

But almost no empirical research has paid attention to potential visitors deciding not to attend trade shows. Rosson and Seringhaus, ${ }^{14}$ analyse visitor behaviour (and that of the exhibitors), highlighting three key phases in the life of a trade show: the prior phase (pre-trade show), the development phase (at-trade show) and the follow-up phase (post-trade show). In the pretrade show phase, the key questions for the visitor are linked to a decision that can be postponed, even for years: should we attend? Among the different aspects of visitor behaviour in this phase, the most relevant one is to disclose the reasons why targeted individuals may decide not to become actual visitors. Rosson and Seringhaus, ${ }^{14}$ emphasise that there is limited information available about the reasons that lead business managers to decide not to attend a trade show. Hough $^{15}$ points out that the major reasons are the lack of time, cost pressures or having to travel long distances. In addition, previous negative experiences at trade shows, like dealing with unskilled personnel (as noted by Tanner and Chonko ${ }^{13}$ ), might also play a part in the no-visit decision. ${ }^{16}$

Nevertheless, these observations have not been confirmed in a specific show setting using currently available methods of analysis; in other words, empirical confirmation does not exist as to which factors or critical deterrents cause a potential visitor not to become an actual one. So, we need to confirm the existence of a disincentive to attend shows that determines the decision of some potential visitors.

\section{Nonattending decision criteria}

Based on the literature review, our starting point is that the nonattendance decision would be the result of perceptions and assessment of 12 different aspects, which could be grouped into three more general criteria (see Table 1). Given the above-mentioned lack of research on nonattendance, we used the research done on reasons to attend as a mirror to reflect the criteria governing the decisions of nonattending. We also conducted exploratory research based on interviews with experts (researchers with background on trade shows, firm managers, trade show organisers and executives of trade show associations) to identify the main criteria used in the decision. The exploratory research basically confirmed that the major criteria used to attend, found in the literature reviewed, could be the main criteria considered by firm managers in not including trade shows in their communication plans. Some reasons for attending might be irrelevant in the decision of nonattending and vice versa, but the main criteria are present in 
Table 1: Criteria and indicators of nonattendance at a trade show

\begin{tabular}{|c|c|c|}
\hline Criteria/dimension & Description of item & Item \\
\hline \multirow[t]{7}{*}{ Product \& Communication } & Lack of institutional support & $\mathrm{v} 1$ \\
\hline & Unfamiliarity with the trade show organiser & v2 \\
\hline & Excessive offer/thematic repetition & v3 \\
\hline & Lack of general information & v4 \\
\hline & The company's preference of other channels of communication & v5 \\
\hline & Absence of a trade show tailored to the company's needs & v6 \\
\hline & There is no tradition in our sector & v12 \\
\hline \multirow{2}{*}{ Location \& Time Convenience } & Inconvenient trade show dates & v7 \\
\hline & Inconvenient event location & v8 \\
\hline \multirow[t]{3}{*}{ Costs \& Returns } & Cost of attendance & v9 \\
\hline & Unavailability of suitable staff & v10 \\
\hline & Perception that the activity is not profitable for the company & v11 \\
\hline
\end{tabular}

both types of decisions. These major criteria are: the fit of the trade show and the awareness and knowledge that potential customers have about it, ${ }^{10,11,13}$ the convenience of the scheduled dates and of the venue, ${ }^{15}$ and the perceived costs and returns. ${ }^{13,15}$ We will call these criteria: Product \& Communication (P\&C), Location \& Time Convenience (L\&TC) and Costs \& Returns (C\&R), respectively (see Table 1).

The theoretical discussion about the composition of the criteria involved is as follows:

'Product \& Communication' (P\&C), includes the variables that reflect the mismatching of the product offered with the needs of potential customers (v12, v3, v5 and v6), and the lack of awareness of the trade show among potential visitors due to communication problems (v1, v2 and v4).

The value of the product offered by trade show organisers to visitors has three basic levels: the generic value (trade show as an effective tool to enhance competitiveness of visitors), the category value (thematic focus on the interest of potential visitors) and the brand value (leadership in attracting the relevant incumbents). These three levels have, respectively, very close negative links with items v12 (there is no tradition in our sector), v5 (visitors prefer other communication channels with suppliers), v6 (the lack of trade shows matching the potential visitor's needs) and v3 (excessive and repetitive trade shows).

Communication problems also play a relevant role in the potential failure to get the desired number and quality of visitors. As in the product case, the failure of communication to potential visitors happens at the generic level (unawareness of trade shows), the category level (unawareness of the thematic trade shows) and at the brand level (unawareness of the leading trade show). These three levels are well captured by items v4 (lack of general information), v1 (lack of institutional communication to targeted potential visitors) and v2 (lack of information about the leading trade show).

'Location \& Time Convenience' (L\&TC), considers the inconvenience of the trade show venue (v8), as well as the inconvenience of the dates (v7). The basic dimensions of an effective delivery of the trade show are location and time, since they together determine the size of the market. First, travel costs and the availability of different transportation modes vary depending on the venue, so that the size of the potential market depends very much on the choice of the venue. Secondly, seasonality is an important issue in trade shows: visitors cannot allocate human resources to visit trade shows during peak demand periods so they have to explore alternatives that better coordinate with their time schedule. Therefore, the choice of dates has a serious impact on the trade show's ability to attract the desired attendance. The impact of both the choice of venue and of the show dates on the decision of potential visitors to attend the trade show is adequately reflected by items v8 and v7. 
'Costs \& Returns' (C\&R), includes the variables of perceived costs and expected returns derived from the decision to attend a trade show: the costs of attendance (v9), inability to release specialised personnel to attend (v10) and the perception that the event will not be profitable (v11). Altogether, it deals with the economic balance of attending trade shows: the restriction of direct perceived costs and the indirect expectation of insufficient returns.

\section{THE EMPIRICAL SETTING AND THE MODELLING}

\section{The empirical setting}

In our empirical context, the target segment analysed for the trade show organiser is made up of retailers. This permits us to pursue the objectives of the investigation with a broad perspective that favours the application of the conclusions to a wide variety of events. The information was gathered by a market research institute using structured questionnaires in personal interviews to retailers in Zaragoza, a large Spanish city. The city is within a triangle with vertices in Madrid, Barcelona and Valencia, which are the major venues of trade shows in the country. Each of them hosts different trade shows with a particular focus on retailers. This location allows local retailers to choose among a wide variety of trade shows with different dates and venues within a $300 \mathrm{~km}$ radius. The sample of 262 interviewed retailers was selected from the population, which was the object of the study, that is, the total of retail businesses in the city, with quotas regarding the different retailing activities $(k=1.96$, error $= \pm 5.78$ per cent $)$. The number of retailers, who said that they had previously attended one or more trade shows as professional visitors, was 42 per cent. Retailers specialising in home furnishings had the highest rate of attendance $(80$ per cent), followed by those specialising in outwear and footwear (52 per cent) and finally by those in the food sector (31 per cent). The rest of the sample, 58 per cent (151) had never decided to attend a trade show.

We will restrict our attention to these retailers who, for some reason, did not attend any trade show as professional visitors. The questionnaire included specific questions (12 items) about the reasons influencing the decision of not attending trade shows. Questions about retailers' perceptions - each item - were measured with five-point scales, from 'not important at all' (1) to 'very important' (5) to determine the nonattendance decision.

\section{The modelling of the decision to not attend trade shows}

In order to model the decision of nonattendance by the targeted individual, the first task is to look for the possible association of specific reasons for not attending in higher order concepts or factors. The applied technique is CFA (First and Second Order Models - statistical program EQS 6.1-). This analysis seeks to confirm a measurement model of a latent variable, which we will call Disincentive to Attend Trade Shows (DATS).

First of all, Cronbach's alpha coefficients were calculated for the total list of items, getting a value of 0.85 after item v12 was eliminated from the list because the item to total correlation was less than $0.3^{17}$ and, for P\&C, L\&TC and C\&R criteria, where the values were $0.82,0.92$ and 0.78 , respectively. Then, we proceeded to check if these dimensions could be used as effective measurements of the disincentive to attend. To do so, we first rejected the possibility that the 11 items make up just one dimension, and afterwards we estimated a First Order CFA (CFA-FO) with three dimensions (P\&C, L\&TC and C\&R).

All three dimensions have significant standardised weights above the 0.5 value, which indicates convergent validity of the scale. ${ }^{18}$ Also, the reliability coefficients: $\mathrm{CF} 1,{ }^{19} \mathrm{CF} 2{ }^{20}$ and the multiple correlation coefficient to the square to estimate the reliability of the indicators Bollen $^{21}$ and Mueller ${ }^{22}$ ), have values greater than those recommended (Table 2).

Given the high correlations among these dimensions, we proceeded further to estimate a Second Order CFA (CFA-SO). The CFA Model estimated is shown in Figure 1. The obtained goodness-of-fit indicators of the model permit us to accept DATS as a multidimensional variable formed by three dimensions and 11 items (Table 3). The coefficients estimated of the three first order 
Table 2: CFA-FO and CFA-SO results

\begin{tabular}{|c|c|c|c|c|c|c|c|c|c|c|}
\hline \multicolumn{5}{|c|}{ CFA-FO-3D } & \multicolumn{6}{|c|}{ CFA-SO-3D } \\
\hline & PC & LTC & CR & $R^{2}$ & & PC & LTC & CR & DATS & $R^{2}$ \\
\hline $\mathrm{v} 1$ & 0.90 & & & 0.82 & $\mathrm{v} 1$ & 0.90 & & & & 0.81 \\
\hline v2 & 0.76 & & & 0.57 & v2 & 0.76 & & & & 0.57 \\
\hline v3 & 0.91 & & & 0.82 & v3 & 0.90 & & & & 0.82 \\
\hline v4 & 0.89 & & & 0.80 & v4 & 0.89 & & & & 0.80 \\
\hline v5 & 0.90 & & & 0.80 & v5 & 0.90 & & & & 0.80 \\
\hline v6 & 0.84 & & & 0.70 & v6 & 0.84 & & & & 0.70 \\
\hline v7 & & 0.91 & & 0.83 & v7 & & 0.91 & & & 0.83 \\
\hline v8 & & 0.95 & & 0.89 & v8 & & 0.95 & & & 0.89 \\
\hline v9 & & & 0.87 & 0.75 & v9 & & & 0.87 & & 0.75 \\
\hline v10 & & & 0.90 & 0.80 & $\mathrm{v} 10$ & & & 0.90 & & 0.80 \\
\hline v11 & & & 0.85 & 0.72 & v11 & & & 0.85 & & 0.72 \\
\hline CF1 & 0.75 & 0.86 & 0.76 & & CF1 & 0.75 & 0.86 & 0.76 & 0.77 & \\
\hline CF2 & 0.94 & 0.92 & 0.90 & & CF2 & 0.94 & 0.92 & 0.90 & 0.91 & \\
\hline $\mathrm{PC}$ & 1 & & & & $\mathrm{PC}$ & & & & 0.95 & 0.92 \\
\hline LTC & 0.70 & 1 & & & LTC & & & & 0.73 & 0.54 \\
\hline $\mathrm{CR}$ & 0.80 & 0.68 & 1 & & $\mathrm{CR}$ & & & & 0.93 & 0.87 \\
\hline
\end{tabular}

CFA-FO-3D: First order confirmatory factorial analysis model with three dimensions. CFA-SO-3D: Confirmatory factorial analysis model (one second order dimension and three first order dimensions). Standardised solution.

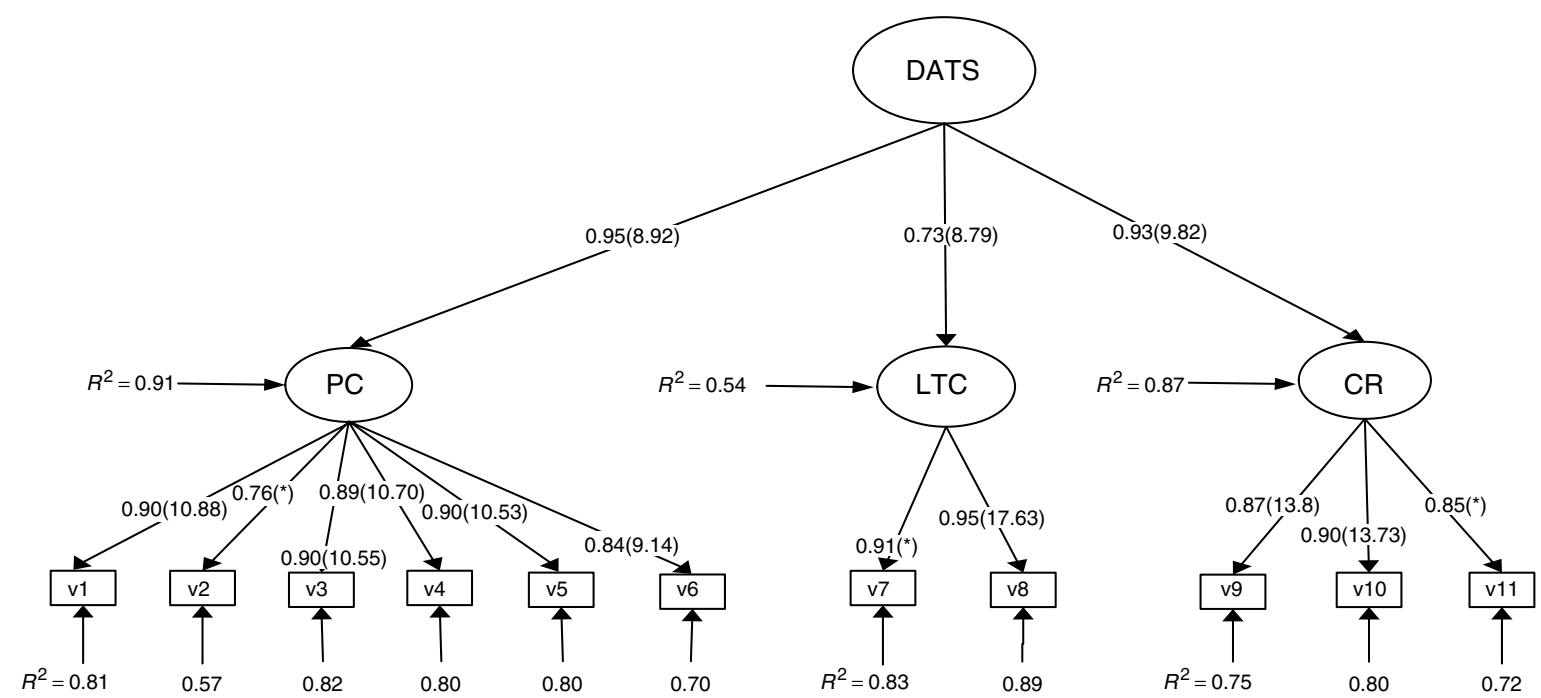

Figure 1: DATS measurement model

Table 3: Goodness-of-fit measures of CFA-SO

\begin{tabular}{lllllllllll}
\hline Estimated models & g.I. & $\boldsymbol{p}$-value & $\chi^{2}$ & $\chi^{2} / \mathbf{g l}$ & RMSEA & GFI & AGFI & NFI & NNFI & CFI \\
\hline CFA-SO-3D & 41 & 0.8862 & 53.6787 & 1.30 & 0.045 & 0.922 & 0.875 & 0.946 & 0.982 & 0.986 \\
\hline
\end{tabular}

dimensions as formative indicators of DATS rise to $0.95,0.73$ and 0.93 , respectively, which confirms a major presence of the P\&C factor 'Product and Communication' in the DATS. Reliability coefficients of the second order factor are 0.77 (Fornell and Larcker coefficient) and 0.91 (construct reliability).

As a corollary, it can be said that trade show organisers targeting retailers are missing a large part - more than 50 per cent in our context - 
of the target market, and that to recover it they should allocate their marketing efforts to actions oriented towards diminishing the negative impact of the three factors. The priorities would be to manage factor $\mathrm{P} \& \mathrm{C}$ and factor $\mathrm{C} \& \mathrm{R}$ : obtaining institutional support, differentiating events and increasing communication (P\&C), to decrease perceived costs and to increase profit expectations (C\&R). The third factor - L\&TC - would have a lower priority but it should be also treated as a set of actions that could generate new visitors.

\section{THE SIZE OF THE POTENTIAL MARKET}

Once the reasons not to attend trade shows have been incorporated to a model, it is necessary to evaluate how much it can help the managers of trade shows, that is, to see the response of the potential market to improvements in the design and communication of the trade show, in its place and time conditions, and in the economic expectations of visitors. If these improvements are costly, trade show managers should have estimations about the response of the targeted potential visitors in order to decide how far they should go with improvements. A primary evaluation of the extent of the response takes in the size and characteristics of the potential market: what percentage of the current market is actually interested in trade shows? The first condition to be part of a potential market is to have some interest in the product/service, since lack of interest should raise questions among organisers.

To assess the size of the current potential market, a cluster analysis is done to identify the individuals actually interested in attending trade shows and to check for differences in their behavior relative to the decision of nonattendance. The application is implemented using first hierarchical cluster procedures and square Euclidean distance as a measure of similarity among the objects. The development of the clusters was accomplished by using average linkage inter-groups, and the dendrogram and agglomeration schedule were used to identify the atypical observations of the sample, which were then eliminated. The result of the process substantiates the existence of two groups of differentiated retail businesses, within the segment of those deciding not to attend professional trade shows due to the evaluations of failure to communicate, trade show's inconvenience and perception of costs. The results are shown in Table 4 .

Group one is the largest, formed by 81 retail businesses that make up 53 per cent of nonattendees. The main differential characteristic of this group is that respondents show much higher mean values for all the items included in the three factors. That is, they identify the items with their actual reasons not to attend trade shows. This could be evidence that the group is integrated by retail businesses that decide not to attend trade shows, due to the incidence of the three factors identified as causing a disincentive to visit a trade show. For each one of these criteria, the variables presented a mean score higher than three on a scale of five points, which leads us to conclude that all three have a strong influence on the decision not to attend.

Group two is made up of 33 retailers, 22 per cent of nonattendees. The low mean values of all the items included in the model of the decision of not attending trade shows suggests that their decision is based on some other reason than the ones included in the model.

The next step is to use nonhierarchical techniques departing from the initial seed points, to adjust or 'fine-tune' the results from the previous hierarchical procedures. Next, the process is repeated allowing the random selection of the initial seed points to provide a validity check for stability of the cluster solution. The solution of two clusters results in groups of practically the same size as those obtained with the previous solution and the cluster profiles are very similar. The connection and stability of the solution between the hierarchical and nonhierarchical methods confirms a consistency in the result of the clusters.

Once the presence of the two analysed groups is detected, we proceed to their interpretation through observed variables, with additional data not previously included in the cluster, and valued by the same surveyed group. These additional data 
Table 4: Cluster analysis results

\begin{tabular}{|c|c|c|c|c|c|}
\hline Criteria & Variables & $\begin{array}{l}\text { Mean/Group } 1 \\
\text { (81 cases) }\end{array}$ & $\begin{array}{l}\text { Mean/Group } \\
2 \text { (33 cases) }\end{array}$ & $\boldsymbol{F}$ & Sig. \\
\hline Product \& & Lack of institutional support (v1) & 3.33 & 1.88 & 56.976 & 0.000 \\
\hline \multirow[t]{5}{*}{ Communication } & $\begin{array}{l}\text { Unfamiliarity with the trade show } \\
\text { organiser (v2) }\end{array}$ & 3.28 & 1.85 & 54.819 & 0.000 \\
\hline & Excessive offer, thematic repetition (v3) & 3.10 & 1.39 & 101.648 & 0.000 \\
\hline & Lack of general information (v4) & 3.27 & 1.67 & 81.149 & 0.000 \\
\hline & $\begin{array}{l}\text { Company's preference of other channels } \\
\text { of communication (v5) }\end{array}$ & 2.80 & 1.67 & 40.248 & 0.000 \\
\hline & $\begin{array}{l}\text { Absence of a trade show 'tailored to } \\
\text { company's needs' (v6) }\end{array}$ & 3.14 & 1.76 & 46.374 & 0.000 \\
\hline Location \& Time & Inconvenient trade show dates (v7) & 3.46 & 2.73 & 8.095 & 0.000 \\
\hline Convenience & Inconvenient event location (v8) & 3.56 & 2.55 & 16.939 & 0.000 \\
\hline \multirow[t]{3}{*}{ Costs \& Returns } & Cost of attendance (v9) & 3.53 & 1.88 & 69.126 & 0.000 \\
\hline & No availability of suitable staff (v10) & 3.31 & 1.79 & 60.253 & 0.000 \\
\hline & $\begin{array}{l}\text { Perception that the trade show will not be } \\
\text { profitable (v11) }\end{array}$ & 3.59 & 2.52 & 26.327 & 0.000 \\
\hline
\end{tabular}

are selected applying the proof of Pearson's chisquare. The results provide two useful variables: the interest in attending trade shows to make business relationships $\left(\chi^{2}(4)=8.889, p\right.$-value $<0.10)$, and the main activity of the retail business $\left(\chi^{2}(4)=12.781, p\right.$-value $\left.<0.10\right)$. The resulting corrected categorised residuals verify the existing association among the categories of each analysed variable and the obtained groups (Table 5). The tests used for the two variables (Goodman's Tau and Kruskal coefficients for the nominal variable 'main activity of the retail business', and Kendall's Tau test for the ordinal variable, 'interest in attending....') confirm an association that is greater for the latter than for the former.

The clustering role of one particular retail activity might be the result of the supply and demand conditions of the local market researched. In our empirical setting, Group 1 is dominated by food retailers suggesting that in this retail activity, attending trade shows is a common practice. The supply of thematic trade shows, the relative (in)efficiency of other communication channels and the historical background explain the uneven attendance ratio among different retail activities. In other cities, countries or areas, other type of retailers may show up as the most inclined to attend trade shows.

This clustering provides good evidence to answer our first question: what is the gap size between the target segment and the potential market in the segment? The first of the two clusters is formed primarily by small retail food businesses who are interested in attending trade shows, but have some reasons for not having done so in the past. Predictably, trade show organisers who provide solutions to them by engaging in better pre-trade show communication about the event, emphasising the advantages offered by the trade show as a means to establish business relationships, have the greatest possibility to attract these potential visitors to the trade show. The second cluster is formed by businesses whose principal activity is not food and who do not consider attendance at a trade show useful in establishing business relationships. These retailers, summing up the 13 per cent of the total segment, show a very low potential of becoming actual visitors in the short term.

\section{THE NONATTENDANCE DECISION OF THE TARGET SEGMENT THAT IS PART OF THE POTENTIAL MARKET}

If retailers in Group 2 have no intention to attend trade shows in the short term, disregarding improvements in the offerings of organisers, then most of the marketing resources allocated to attract them would be wasted. But a further and more relevant problem arises: does the inclusion 
Table 5: Characteristics of the groups

\begin{tabular}{ll}
\hline Group 1 & Group 2 \\
\hline Small retail food business & $\begin{array}{l}\text { Small retail businesses: } \\
\text { textiles, drugstore and } \\
\text { perfumery, home furnishings } \\
\text { and stationers }\end{array}$ \\
$\begin{array}{l}\text { Interest in attending the } \\
\text { trade show to form business } \\
\text { relationships }\end{array}$ & $\begin{array}{l}\text { trade show to form business } \\
\text { relationships }\end{array}$ \\
\hline
\end{tabular}

of members of the target segments, which are not part of the potential market, lead to wrong customer acquisition strategies? To assess the magnitude of this problem, we apply our model with a multi-sample analysis to both groups of retailers (all part of the target segment).

The results provided in Table 6 show significant differences in the expected direction. The only factor, in Group 2, which would have some impact on the not-attending decision for the not interested retailers, is $\mathrm{C} \& \mathrm{R}$. But our specific concern is the comparison of the model estimates when applied to the 151 individuals of the target segment not attending trade shows, and to the group of interested retailers (only the 81 individuals who might be considered as actual potential customers). When the model is applied to only the individual retailers who are interested in attending trade shows to establish business relationships (Group 1), the same three factors remain as the pillars of the decisions of nonattendance. But there are two major and interesting differences: one is the large change in the relative importance of the factors; another is the disappearance of two specific items of the $\mathrm{P} \& \mathrm{C}$ factor in Group 1.

About the relative importance of the factors, in Group 1, the C\&R factor emerges as most responsible for the decision not to attend trade shows. Then, with similar weights, $\mathrm{P} \& \mathrm{C}$ and L\&TC factors have a lesser influence. If trade show organisers would rely on the total number of nonattendees for the design of customer acquisition initiatives, they would be confident that by providing more dates and/or venues for particular events (L\&TC dimension) they would be able to attract more visitors. Then, the assessment of the profitability of adding events to different venues or of extending their duration would be made on an inflated base and its impact overestimated. Alternatively, organisers would focus on the $\mathrm{P} \& \mathrm{C}$ dimension, concluding that increases in the communication budget could have a profitable response by attracting new customers. Again, the estimated effects of allocating more resources in communication would be overestimated. On the contrary, by adjusting the target segment to those retailers actually interested, organisers could realise that their major efforts should be addressed to the improvement of the return expectations of visitors and the reduction of their perceived costs.

The second major difference, is that the lack of institutional support and the excessive offer of similar events ( $\mathrm{v} 1$ and $\mathrm{v} 3$, respectively) included in the first dimension became no significant indicating that there were no problems with the external support and the differentiation of trade shows. As a consequence, there would be no gain of potential customers by increasing efforts to get additional institutional support and by modifying the trade show offering.

The results point to the existence of two levels in the decision to attend trade shows. There is a part of the target segment that does not see trade shows as an adequate channel to establish business relationships, and they are currently not reviewing their nonattending decision. Thus, the evaluation is made on the basis of only one criterion: costs and expected returns. Those who believe that building business relationships is, however, important for their company are further along in their decision-making process. They are aware of the benefits that would accrue from a visit to trade shows and are therefore assessing their decision with additional criteria other than the costs-returns. So, although the cost--returns considerations are the leading criteria, the other two criteria also play a role in the decision.

\section{CONCLUSIONS AND MANAGERIAL IMPLICATIONS}

We have analysed the discrepancy between targeted and potential customers in one empirical setting - trade shows organisers targeting retail firms - in which the effectiveness in reaching 
Table 6: Multi-sample model results*

\begin{tabular}{|c|c|c|c|c|c|c|c|c|c|c|c|}
\hline \multicolumn{6}{|c|}{ Group 1} & \multicolumn{6}{|c|}{ Group 2} \\
\hline & PC & LTC & CR & DATS & $R^{2}$ & & PC & LTC & CR & DATS & $R^{2}$ \\
\hline v1 & n.s. & & & & & v1 & 0.99 & & & & \\
\hline v2 & $\star \star$ & & & & & v2 & $\star \star$ & & & & \\
\hline v3 & n.s. & & & & & v3 & 0.29 & & & & \\
\hline v4 & 0.67 & & & & & v4 & 0.63 & & & & \\
\hline v5 & 0.83 & & & & & v5 & n.s. & & & & \\
\hline v6 & 0.93 & & & & & v6 & 0.43 & & & & \\
\hline v7 & & 1.26 & & & & v7 & & 1.32 & & & \\
\hline v8 & & ** & & & & v8 & & 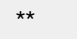 & & & \\
\hline v9 & & & 1.28 & & & v9 & & & 0.85 & & \\
\hline v10 & & & 1.44 & & & v10 & & & 0.80 & & \\
\hline v11 & & & $\star \star *$ & & & v11 & & & $\star *$ & & \\
\hline CF1 & 0.53 & 0.80 & 0.52 & & & & & & & & \\
\hline CF2 & 0.72 & 0.82 & 0.68 & & & & & & & & \\
\hline$P C$ & & & & 0.64 & 0.41 & $\mathrm{PC}$ & & & & n.s. & \\
\hline LTC & & & & 0.55 & 0.30 & LTC & & & & n.s. & \\
\hline CR & & & & 0.98 & 0.96 & CR & & & & 0.99 & 0.99 \\
\hline
\end{tabular}

*Nonstandardised solution for v's.

**Fixed to 1.

n.s. nonsignificative, statistic significant at the $5 \%$ level other cases.

the potential customers really interested in the product is a crucial point in the marketing plan. Retail firms make up one of the segments most widely targeted by trade shows, but it is also quite a heterogeneous group so that it is expected that a relevant number of retailers might not be potential customers (ie visitors) of trade shows.

Based on this group, we found that there are three major dimensions that play a relevant role in explaining the decision of not attending trade shows: (un)suitability of the trade show and communication problems, (in)convenience of time and place, and costs or insufficient returns. The common practice would lead trade show organisers to intensify their marketing efforts in seeking institutional support, developing schedules with fewer and more differentiated events, increasing communication budgets and providing access to cost reductions for retailers.

But in a second step, we found that a relevant part of nonattendees were actually not interested in trade shows. In fact, the consideration of these individuals generated not only an overestimation of the segment's market potential, but also a misunderstanding of the reasons given by retailers for not attending trade shows. When excluding noninterested individuals from the analysis, two major changes appeared: the relative importance of the dimensions explaining the nonattendance was significantly altered and two items of the $\mathrm{P} \& \mathrm{C}$ factor became insignificant. Concerning the first, the real major problems in not attending trade shows are not those gathered in the 'Product and Communication' factor but those associated with the costs and the expected returns (see Figure 2). Secondly, contrary to what the model estimation suggested for the whole segment, organisers should not anticipate gains of potential customers by increasing their efforts to get additional institutional support or by modifying the trade show offering.

Two managerial implications stem from this analysis. First, when the identification, within the targeted segment, of potential customers really interested in the product is not too costly, there is a great improvement in marketing productivity, saving communication efforts that otherwise would be indiscriminately addressed to the whole segment. Secondly, companies should not base their marketing strategies for customer acquisition on the information gathered from the generality of noncustomers in the targeted segment. Only 


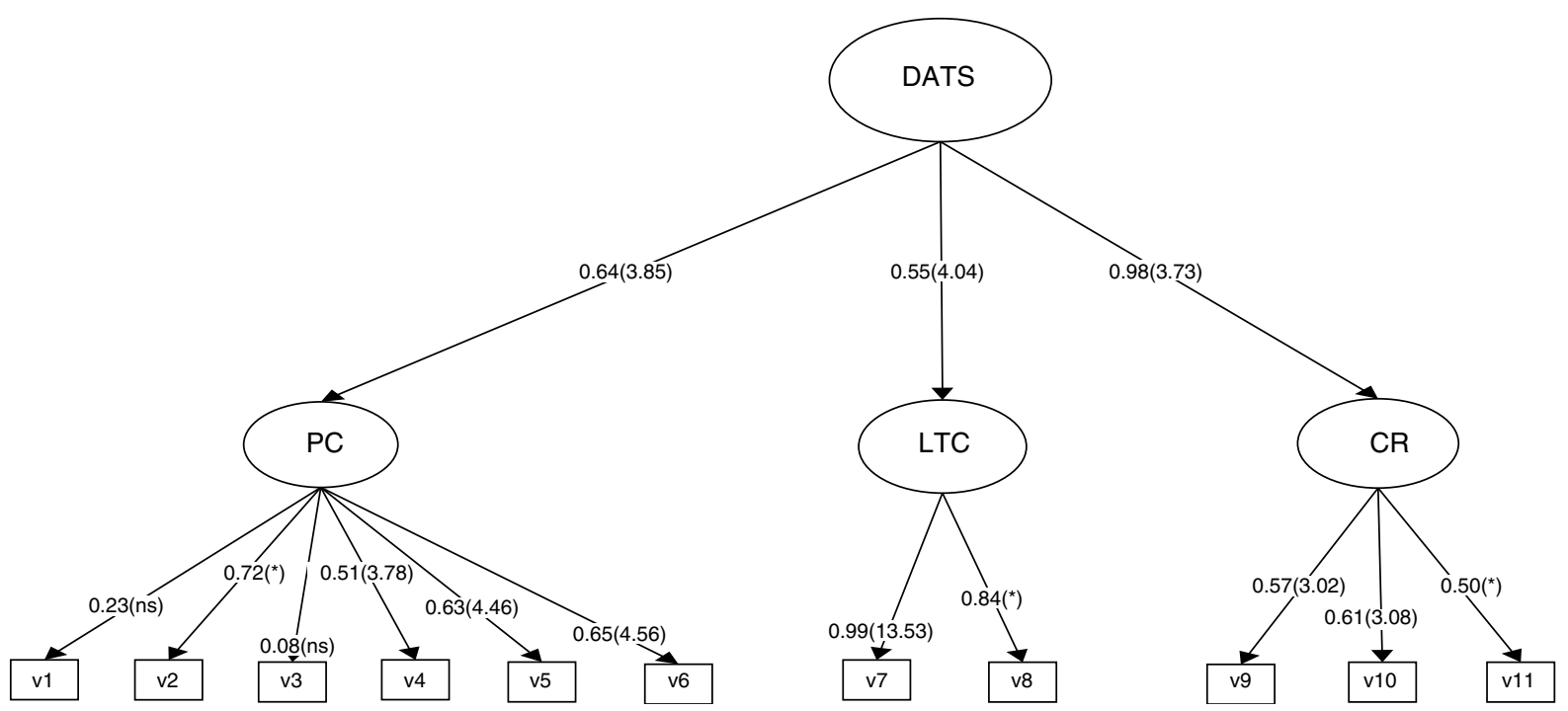

Figure 2: DATS measurement model of group $1^{*}$ (*Standardised solution)

potential customers should be considered in the analysis to design the marketing strategy to attract new customers of the targeted segment; otherwise, actions could be misleading and unproductive.

More specifically, for the organiser's communication plan, our findings suggest a two-fold perspective when targeting nonattendants. First, a long-term perspective focused on enlarging the potential market (in our case, shifting individuals from Group 2 to Group 1) in which the communication content should mix two basic arguments: trade shows are a good channel for building and developing the relationships that are crucial for business and the expected returns exceed the costs of attending.

Secondly, a medium-term perspective that aims to convert potential customers into actual attendants. The communication targeting this group is more focused; the location and time convenience is now a secondary decision criterion. Trade show organisers may recruit new visitors from neighbouring or distant locations at different times of the year, to the extent that the delivered trade shows are seen as valid tools for the achievement of their business objectives. The costs-returns criterion is basic, so that lowering the perceived costs, and favouring positive expectations about the returns of attending trade shows should be the most effective arguments in turning these individuals into actual visitors.

The study also has limitations that we must bear in mind. First, the local character of the sample might be influencing our finding about the retail activity. When targeting potential customers, the retail activity seems to be an effective discriminating factor, but organisers should identify — in their particular market areas - those retail activities in which trade shows are considered important in the achievement of successful business relationships. Secondly, the selection procedure of the sample, suitable to represent the population studied, presents an advantage in obtaining conclusions that fundamentally affect smaller businesses. This benefit becomes somewhat of a disadvantage since it does not, however, permit a direct interpretation of decisions made by larger companies. So, further research must be undertaken to assess the validity of our measurement scale of DATS for this kind of business.

Also, more complementary research would be needed from the perspective of exhibitors in order to provide a more focused view of the DATS. This perspective would allow a greater understanding of the disincentive at the brand or company level, which would complement the findings provided in this paper at the product level. 


\section{Acknowledgments}

The authors express their gratitude for the assistance received from FUNDEAR and MICYT-FEDER SEJ2005-06603/ECON. This work was completed under the framework of the CREVALOR research group.

\section{References}

1 Godar, S. H. and O'Connor, P. J. (2001)‘Same time next year Buyer trade show motives', Industrial Marketing Management, Vol. 30, pp. 77-86.

2 Smith, T. M., Hama, K. and Smith, P. M. (2003)'The effect of successful trade show attendance on future show interest: Exploring Japanese attendee perspectives of domestic and offshore international events', Journal of Business and Industrial Marketing, Vol. 18, No. 4/5, pp. 403-418.

3 AFE, Spanish Trade Shows Association (2006)'A case for the value of trade shows. Their importance, utility and advantages. www.afe.es.

4 Cox, J. M., Sequeira, I. K. and Bock, L. L. (1987)‘1986 Trade show trends: Audience quality remains high’, Business Marketing, Vol. 72, No. 5 (May), pp. 108-111.

5 Kijewski, V., Yoon, E. and Young, G. (1992)'1986 Trade shows: How managers pick their winners', ISBM, Institute For The Study Of Business Markets, Report 15-1993, 30 October.

6 Blattberg, R. C. and Deighton, J. (1996)'Manage marketing by the customer equity test', Harvard Business Review, Vol. 74(July-August), pp. 136-144.

7 Berger, P. D., Bolton, R. N., Bowman, D., Briggs, E., Kumar, V., Parasuraman, A. and Creed, T. (2002)'Marketing actions and the value of customer assets', Journal of Service Research, Vol. 5(August), pp. 39-54.

8 Reinartz, W. and Kumar, V. (2003)'The impact of customer relationship characteristics on profitable lifetime duration', Journal of Marketing, Vol. 67, No. 1, pp. 77-99.

9 Rust, R., Lemon, K. and Zeithaml, V. (2004)'Return on marketing: Using customer equity to focus marketing strategy', Journal of Marketing, Vol. 68, No. 1, pp. 109-127.
10 Moriarty, R. and Spekman, R. (1984)'An empirical investigation of the information sources used during the industrial buying process', Journal of Marketing Research, Vol. 21, No. 2, pp. $137-147$.

11 Bello, D. C. (1992)'Industrial buyer behavior at trade shows: Implications for selling effectiveness', Journal of Business Research, Vol. 25, No. 1, pp. 59-80.

12 Hansen, K. (2004)'Measuring performance at trade shows: Scale development and validation', Journal of Business Research, Vol. 57, No. 1, pp. 1-13.

13 TannerJr., J. F. and Chonko, L. B. (1995)‘Trade show objectives, management, and staffing practices', Industrial Marketing Management, Vol. 24, pp. 257-264.

14 Rosson, P. J. and Seringhaus, F. H. R. (1995)'Visitor and exhibitor interaction at industrial trade fairs', Journal of Business Research, Vol. 32, No. 1, pp. 81-90.

15 Hough, J. (1988)'Attitudes and opinions of computer executives regarding attendance information technology events', Research Report, Audience Characteristics \#1080, Trade Show Bureau, East Orleans, MA, October.

16 Trade Show Bureau (1989)'Analysis of trade show and conference attendees regarding their opinions of why (or why not) they attend various trade shows and conferences', Research Report, Audience Characteristics \#1100, Trade Show Bureau, East Orleans, MA, November.

17 Nurosis, M. (1993) ‘SPSS: Statistical Data Analysis', SPSS Inc: Chicago, IL.

18 Anderson, J. C. and Gerbing, D. W. (1988) 'Structural equation modelling in practice: A review and recommended two-step approach', Psychological Bulletin, Vol. 103, No. 3, pp. 411-423.

19 Fornell, C. and Larcker, D. F. (1981)'Evaluating structural equation models with unobservable variables and measurement error', Journal Marketing Research, Vol. 18, pp. 39-50.

20 McDonald, R. P. (1985)'Factor Analysis and Related Methods', Hillsdale, NJ: Lawrence Erlbaum Associates, Publishers.

21 Bollen, K. A. (1989)'Structural Equations with Latent Variables', John Wiley, New York.

22 Mueller, F. (1996)'Human resources as strategic assets: An evolutionary resource-based theory', Journal of Management Studies, Vol. 33, No. 6, pp. 757-786. 